\title{
Studies on nutritional facts of spring herbs collected from Bulgarian market.
}

\author{
Maria S Atanassova1*, Muhammad Shahzad Aslam², Somesh Sharma ${ }^{3}$, Manisha Nigam ${ }^{4}$, Lyubomir M \\ Atanassov $^{5}$, Ardalan Pasdaran ${ }^{6}$, Mohammad Ayaz Ahmad \\ ${ }^{1}$ Scientific Consulting, Chemical Engineering, UCTM-Sofia, Bulgaria \\ ${ }^{2}$ Assistant Professor, Rashid Latif College of Pharmacy, Lahore, Pakistan \\ ${ }^{3}$ Associate Professor, School of Bioengineering and Food Technology, Shoolini University, Solan, India \\ ${ }^{4}$ Assistant Professor, Department of Biochemistry, Hemvati Nandan Bhauguna Garhwal University, Garhwal, \\ Uttarakhand, India \\ ${ }^{5}$ Student, MIPT, Moscow, Russia \\ ${ }^{6}$ Assistant Professor, Medicinal Plants Processing Research Center, Shiraz University of Medical Sciences, Shiraz, Iran \\ ${ }^{7}$ Assistant Professor, Physics Department, College of Science, University of Tabuk, Saudi Arabia
}

\begin{abstract}
Herbs are ancient medicines rich in various phenolic and aromatic compounds, although used only in culinary applications. The influence of regular consumption of spring herbs from plant foods rich in naturally occurring antioxidants from plant foods, oxidative stress, cardiovascular risk and gaining in health effect was studied. The dietary fibers present in these natural spring herbs also play an important role in preventing risk against several diseases. At the same time it is also very important to know the nutritional facts such as contents of lipids, proteins and carbohydrates and their energy values in different foods. Hence, the aim of the present study is to carry out the physicochemical analysis of different spring herbs collected from Bulgarian markets. The five different spring herbs viz Atriplex, Spinacia, Rumex, Rumex acetosa and Utrica were collected and analyzed for various characteristics such as total phenolic and total flavonoid contents, antioxidants activity, total protein, total lipids, insoluble dietary fibers, total carbohydrates and sugar.
\end{abstract}

Keywords: Nutrition facts, Physicochemical analyses, Atriplex, Spinacia, Rumex, Rumex acetosa, Utrica.

Accepted on July 13, 2018

\section{Introduction}

"Let food be thy medicine and medicine be thy food" was expressed by Hippocrates more than two thousand years ago and the health benefits of natural food products have been considered since ancient times $[1,2]$. Herbs are ancient medicines rich in various phenolic and aromatic compounds, but have only culinary applications. Common spring herbs belong to various plant families and differ considerably in various characteristics such as taste, aroma and chemical constituents.

The antioxidant activity of culinary spring herbs and their constituent compounds has been their most widely research aspect, along with their antimicrobial activity. Spring herbs and their compounds have high antioxidant activity [3]. Antioxidants are the compounds that can delay or inhibit the oxidation of lipids or other molecules by inhibiting the initiation or propagation of oxidative chain reactions [4]. Redox active compounds which help to prevent the radical formation or remove them before damage can occur or repair oxidative damage. They eliminate damaged molecules by directly scavenging or neutralizing free radicals or other Reactive Oxygen Species (ROS) and Reactive Nitrogen Species (RNS). Oxidative damage to cells and macromolecule is considered to be the cause of several diseases such as coronary heart disease, a cataract genesis, various neurodegenerative diseases including Alzheimer's disease, cancer, and aging oxidative injury involves free radical-induced damage from both endogenous and exogenous sources [4,5]. Many scientific papers have focused on the relationship between free-radical-induced oxidative stress and the progressive increase in the risk of disease [6]. The incidence of chronic diseases is higher in the elderly [6], but conditions that generate various pathologies start in childhood and adolescence [6]. In Europe, obesity is becoming a serious problem in Bulgaria, a large prevalence of overweight and obesity was observed in school subjects [7]. In addition, children of normal weight could become obese if they did not follow a balanced nutrition regimen [6]. Most young people lead a sedentary life and make common nutritional errors, among which we highlight an insufficient consumption of plant products [6].

Atriplex species (Atriplex hortensis L.) commonly known as red orach, French spinach or garden orache belong to family Amaranthaceae. The species is native to Asia and Europe, but found widely under natural conditions in Canada, United States, Australia, and New Zealand and even in Bulgaria. The plants are dominant in many arid and semi-arid regions of the world, particularly in habitats that combine relatively high on saline and degraded soils have been identified on all continents [8]. The Mediterranean Basin, with 40-50 Atriplex sp., mostly in its southern and eastern bordering areas, is a region where saltbushes have been extensively used as fodder reserves during periods of scarcity (e.g. drought and cold periods), and as a 
supplementary forage resource in arid and semi-arid countries [8]. It is a hardy, annual plant, preferred as a raw or cooked or used like spinach. Due to its blend flavor it is traditionally mixed with sorrel leaves in order to modify the acidity of the latter [4]. Another report says that the flavor is stronger than spinach [4]. The leaves are diuretic, emetic and purgative. They are also said to be a stimulant to the metabolism and an infusion is used as a spring tonic and a remedy for tiredness and nervous exhaustion. They have been suggested as a folk remedy for treating plethora and lung ailments. The leaves are said to be efficacious when used externally in the treatment of gout [4].

Atriplex hortensis L. is a hardy, annual plant belongs to family Amaranthaceae. A. hortensisis is also known as gardenorache, red orach, mountain spinach. Leaves are preferred as raw or cooked or used like spinach. They have a bland flavor and are traditionally mixed with sorrel leaves in order to modify the acidity of the latter. Another report says that the flavor is stronger than spinach. The leaves are diuretic, emetic and purgative. They are also said to be a stimulant to the metabolism and an infusion is used as a spring tonic and a remedy for tiredness and nervous exhaustion. They have been suggested as a folk remedy for treating plethora and lung ailments. The leaves are said to be efficacious when used externally in the treatment of gout.

Spinachia (Spinaciaoleracea L.) belongs to the Amaranthaceous family with the relatively short growing season. It is native to South-West Asia and cultivated through the world as vegetables, it is an important dietary vegetable and a common raw material in the food processing industry [9]. Spinach is not a popular plant in Europe, despite its high content of health-promoting substances. It is the most important leafy vegetable commonly consumed fresh or as canned or frozen products [10]. Spinach is a rich source of polyphenols often associated with beneficial health effects. Their content depends on various factors, such as cultivar or cultivation conditions. These compounds possess an aromatic ring bearing one or more hydroxyl groups and their structures may range from that of a simple phenolic molecule to that of a complex high-molecularweight polymer [9]. Spinach is a good source of carotenoids, flavonoids, vitamin $\mathrm{C}$, vitamin A, vitamin B-6, vitamin $\mathrm{K}$, and minerals such as magnesium, calcium, manganese, potassium and a lot of water $[11,12]$. Epidemiological studies suggest that long-term consumption of diets rich in plant polyphenols offer protection against the development of cancers, osteoporosis, cardiovascular diseases, neurodegenerative diseases and diabetes [13].

The Rumex (Polygonaceae) genus comprises several species, of which leaves and roots have been used in traditional medicine for inflammation, blood purification, and constipation [14]. Because of their high oxalic acid content, they have been implicated in oxalic intoxication, mainly in children [14].The growing interest in many Rumex species has led to the study of their biological activities, namely, the effect of Rumex acetosa in body weight and serum levels of amino acids and minerals, the psychopharmacological and purgative effects of Rumex nepalensis, the antioxidant and cytotoxic agents from Rumex patientia, the antifertility action of Rumex steudelii, the antimicrobial and anti-inflammatory activities of Rumex nernosus and Rumex abyssinicus, the antidiarrheal effect of Rumex maritimus, and the antiviral activity of Rumex bequaertii.

Rumex acetosa L. (Polygonaceae) is a perennial herb that is widely distributed in eastern Asia [15]. The leaf of this plant resembles that of spinach, and the plant is well known for strong acidity in Europe and America, where it is also known as sorrel. Its fresh leaves are eaten as a salad for its acidulous taste. Also, it is served as a salad to patients to assist their convalescence owing to its antiscorbutic properties [16], because total vitamin $\mathrm{C}$ of the leaves varies from 750 to $1200 \mathrm{mg} 100 \mathrm{~g}^{-1}$ [16]. The extract of $R$. acetosa has been reported to have heat-cleaning, diuretic, insecticidal, antimicrobial, and anticancer activities [15]. A decoction of this plant has been used as a folk medicine in Korea to treat arthritis, gastritis and gastric ulcers, and as a substitute for rhubarb, which is an important crude drug for gastrointestinal problems.

The cultivated plants may have phytonutrient profiles and flavors different from the wild plants. In some studies, it has been stated that most of the wild species preserve higher antioxidant capacity, richer flavor and more attractive color, fragrance and aromatic compounds [16].

Utrica (Urticadioica L.) is a widespread wild plant that is also cultivated for specific uses. This herbaceous perennial belonging to the Urticaceae family is very common intemperate climate regions. Its genus name is derived from the Latin urere, which means to sting, and more precisely from uro, meaning to burn by friction. Its bright, dark green and serrated leaves, as well as its stem, are covered with erect glandular hairs containing formic acid and histamine, which are responsible for these unpleasant effects. This plant has been used for centuries in folk medicine to cure a wide range of diseases or disorders such as arthritis, rheumatism, and eczema [17]. A more recent use of polar extracts from nettle roots is the treatment of benign prostatic hyperplasia while its foliar extracts display potent anti-inflammatory action [17]. Utrica (Nettle) extracts are also used in cosmetics and their topical application presents many benefits for skin health (anti-inflammatory and anti-swelling, for example). Nettle is also a common component of shampoo. However, one of the most interesting actions of nettle extracts for cosmetic applications results from their antioxidant and anti-aging properties. Nettle accumulates a number of reactive oxygen species scavengers, which can reduce free radical damage to the skin and therefore has anti-aging effects. To date, the molecule(s) responsible for this action and its rationale are largely unknown. Besides the antioxidant action, anti-aging activity could also be due to the inhibition of degrading enzymes, such as elastase or collagenase, whose actions result in a loss of skin elasticity leading to wrinkles. Among the molecules present in nettle extracts, ursolic acid and quercetin are the most interesting for the development of anti-aging action. Ursolic acid, which mainly accumulated in nettle roots, is a well-known elastase inhibitor whereas quercetin, which mainly accumulated in the leaves, is one of the most prominent antioxidants.

The focus in the present study is a comparative evaluation 
of the total phenolic and total flavonoid contents, antioxidant activity, total protein, total lipids, insoluble dietary fibers, total carbohydrates and sugar in traditional Bulgarian spring herbs as sources for human health.

\section{Material and Methods}

\section{Plant material}

The study covered Atriplex (Atriplex hortensis L.), Spinachia (Spinacia oleracea L.), Rumex (Rumex patientia L.), Rumex (Rumex acetosa L.) and Utrica (Urtica dioica L.). Randomized market sampling was applied. All samples data are stated in the sampling protocol.

\section{Chemical reagents}

Methanol HPLC; Chloroform $\left(\mathrm{CHCl}_{3}\right)$, Diethyl ether, gallic acid, (+)-catechin; Folin-Ciocalteu's phenol reagent; Sodium carbonate $\left(\mathrm{Na}_{2} \mathrm{CO}_{3}\right)$; Sodium Nitrite $\mathrm{NaNO}_{2} ;$ Aluminium (III) chloride $\left(\mathrm{AlCl}_{3}\right)$; Sodium hydroxide $\mathrm{NaOH}$; 2,2-diphenyl-1picrylhydrazyl (DPPH'); Ascorbic acid. All other chemicals were of analytical grade (Sigma Chem. Co).

\section{Sample preparation}

A dry sample of $0.5 \mathrm{~g}$ was weighted and phenolic and flavonoid compounds were extracted with $50 \mathrm{~mL} 80 \%$ aqueous methanol in an ultrasonic bath for $20 \mathrm{~min}$. An aliquot (2 $\mathrm{ml}$ ) of the extracts was ultracentrifuged for $5 \mathrm{~min}$ at 14000 $\mathrm{rpm}$. The extract prepared in this way was used for further spectrophotometric determination of polyphenols.

\section{Total phenolic assay}

The total phenolic content of spring herbs was determined by using the Folin-Ciocalteu assay [18] and was modified [19]. An aliquot $(1 \mathrm{ml})$ of extracts or standard solution of gallic acid $(10,20,40,60,80,100$ and $120 \mathrm{mg} / \mathrm{l})$ was added to $25 \mathrm{ml}$ volumetric flask, containing $9 \mathrm{ml}$ of distilled deionized water ( $\left(\mathrm{dd}_{2} \mathrm{O}\right.$ ). A reagent blank using dd $\mathrm{H}_{2} \mathrm{O}$ was prepared. $1 \mathrm{ml}$ of Folin-Ciocalteu phenol reagent was added to the mixture and shaken. After $5 \mathrm{~min}, 10 \mathrm{ml}$ of $7 \% \mathrm{Na}_{2} \mathrm{CO}_{3}$ solution was added to the mixture. To the solution, the dd $\mathrm{H}_{2} \mathrm{O}$ was added up to the volume of $25 \mathrm{ml}$ and mixed. After incubation for $90 \mathrm{~min}$ at room temperature, the absorbance against prepared reagent blank was determined at $750 \mathrm{~nm}$ with a UV-Vis Spectrophotometer BOECO-Germany. The total phenolic content of spring herbs was expressed as mg gallic acid equivalents per $\mathrm{g}$ (GAE/g). All samples were analyzed in duplicates.

\section{Total flavonoid assay}

The total flavonoid contents were measured by aluminum chloride colorimetric assay [19]. An aliquot (1 ml) of extracts or standard solution of catechin $(10,20,40,60,80,100$ and 120 $\mathrm{mg} / \mathrm{l}$ ) was added to $10 \mathrm{ml}$ volumetric flask, containing $4 \mathrm{ml}$ of distilled deionized water ( $\mathrm{dd}_{2} \mathrm{O}$ ). To the flask was added 0.3 $\mathrm{ml} 5 \% \mathrm{NaNO}_{2}$. After $5 \mathrm{~min}, 0.3 \mathrm{ml}$ of $10 \% \mathrm{AlCl}_{3}$ was added. At $6^{\text {th }} \mathrm{min}, 2 \mathrm{ml} 1 \mathrm{M} \mathrm{NaOH}$ was added and the total volume was made up to $10 \mathrm{ml}$ with $\mathrm{dd}_{2} \mathrm{H}_{2} \mathrm{O}$. The solution was mixed well and the absorbance was measured against prepared reagent blank at $510 \mathrm{~nm}$. Total flavonoid content of spring herbs was expressed as mg catechin equivalents per $\mathrm{g}(\mathrm{CE} / \mathrm{g})$. All samples were analyzed in duplicates.

\section{DPPH assay}

The antioxidant capacity (AOC) of tested samples was determined photo metrically using the DPPH•+ method $[20,21]$. Briefly, $1 \mathrm{ml}$ diluted extract sample was added to $4 \mathrm{ml} 0.004 \%$ solution of DPPH•+in methanol $(0.004 \mathrm{mg} / 100 \mathrm{ml})$. After 60 min solution retention in the dark, the light absorption was measured in $1 \mathrm{~cm}$ standard cuvette at $517 \mathrm{~nm}$ with a UV-Vis Spectrophotometer BOECO-Germany. The reference liquid was methanol. The free radical inhibition (scavenging) was calculated by following formula:

$\mathrm{IC} \%=(($ Absorbance of blank-Absorbance of sample $) /$ Absorbance of blank) $\times 100$

- Absorbance of blank; absorption of the reference liquid not containing extracts (its $0.004 \%$ solution of DPPH ${ }^{*}+$ in methanol)

- Absorbance of sample; absorption of the extract containing sample.

The DPPH' solution was freshly prepared daily, stored in a flask covered with aluminum foil, and kept in the dark at $4^{\circ} \mathrm{C}$ before measurements. The $\mathrm{IC}_{50}$ is a parameter representing the extract concentration, able to inhibit $50 \%$ of the used DPPH*+amount. It was determined by drawing a graph with sample concentration $\mathrm{Cw}$ ( $\mathrm{ml}$ extract/l solvent) on the abscissa and free radical inhibition capacity IC (\%) as ordinate. A series of samples was prepared as already described. The initial extract sample was diluted in a manner to obtain a linear graph which lies in the zone of $0 \%$ to over $50 \%$ radical scavenging capacity.

\section{Physicochemical analyses (Nutrition facts)}

The analyses of Insoluble Dietary Fibers (IDF) were performed according to BDS 5498 after modified method for determination of raw fibers described in the Manual Methods harmonized with the EU requirements and was modified in [22,23]. The insoluble dietary fiber (IDF) content of spring herbs was expressed as percent $(\%)$. Total fat was determined by Soxhlet extraction with diethyl ether or was used a method by $[24,25]$. After modified the method for determination of total fat according to Peshevska was extracted with methanol and chloroform ratio 21. After incubation for $24 \mathrm{~h}$ at room temperature the total fat was calculated by gravimetric. Protein was determined by total nitrogen according to the method by Kjeldahl for protein determination and a conversion factor of 6.25. The analyses of sugar were used the method according to Clarke "Sugars and sugar products". Sugar was determined on the base to reducing Fehling's solution. Moisture content and ash were determined according to BDS EN 12145 and BDS EN $113 \mathrm{~s} 5$. The total carbohydrates were calculated by difference. The total energy was calculated according to Ordinance. All samples were analyzed in duplicates.

\section{Statistical analysis}

All experiments were performed in triplicates. Analysis at every time point from each experiment was carried out in 
duplicate or triplicate. The statistical parameters are calculated in terms of the reproducibility of the experimental data using a statistical package universal ANOVA.

\section{Results and Discussion}

The data presented in Tables 1 and 2 and Figure 1 shows the proximate composition of spring herbs collected from Bulgarian market. The moisture content in different herbs ranged between $86.7 \%-91.0 \%$ with maximum content in plants oRumex sp. The total phenolic content in different herbs ranged between 169.20$212.80 \mathrm{mg}$ GAE/g with highest content in nettle and lowest in Sorrel (Rumex acetosa). It is also reported that phenolic compounds and flavonoids are natural products which have been shown to possess various biological properties related to antioxidant mechanisms [26,27]. Polyphenols have the function to scavenge the free radicals in human body and to help maintain healthy body by scavenging or removing the reactive oxygen species (ROS) [28]. In general, higher total phenolic content resulted in higher antioxidant capacity [29].

Further, the methanolic extract was also subjected to screening for their possible antioxidant activity. DPPH, a stable free radical with a characteristic absorption at $517 \mathrm{~nm}$, was used to study the radical scavenging effects of extracts. As antioxidants donate protons to these radicals, the absorption decreases. The decrease in absorption is taken as a measure of the extent of radical scavenging. Free radical scavenging capacities of the extracts, measured by DPPH assay, are shown in Table 2 and Figure 1. As mentioned above, the $\mathrm{IC}_{50} \%$ is a parameter representing the herb concentration, able to inhibit $50 \%$ of used DPPH amount. A series of samples have prepared as already described. All concentration studied showed free radical scavenging activity. It is evident that the $50 \%$ of inhibition value for Spinacia (Spinacia oleracea) methanol extract seems to

Table 1: Nutrition facts in different herbs.

\begin{tabular}{|c|c|c|c|c|c|c|c|c|}
\hline Herbs & Moisture (\%) & Ash (\%) & Protein (\%) & Total fat (\%) & IDF (\%) & Sugar (\%) & $\begin{array}{c}\text { Carbohydrates } \\
(\%)\end{array}$ & $\underset{\mathrm{kJ} / 100 \mathrm{~g}}{\text { Energy, } \mathrm{kcal} / 100 \mathrm{~g}}$ \\
\hline $\begin{array}{l}\text { Atriplex-Atriplex } \\
\text { hortensis, } \\
\text { (Amaranthaceae) }\end{array}$ & $\begin{array}{c}90.7 \pm 0.1 \\
\operatorname{RDS}=0.11 \\
n=3\end{array}$ & $\begin{array}{c}3.1 \pm 0.1 \\
\mathrm{RDS}=3.23 \\
n=3\end{array}$ & $\begin{array}{c}2.8 \pm 0.1 \\
\mathrm{RDS}=3.57 \\
n=3\end{array}$ & $\begin{array}{c}0.4 \pm 0.1 \\
R D S=25 \\
n=3\end{array}$ & $\begin{array}{c}2.2 \pm 0.1 \\
\mathrm{RDS}=4.55 \\
\mathrm{n}=3\end{array}$ & $\begin{array}{c}0.5 \pm 0.2 \\
R D S=40 \\
n=3\end{array}$ & 3.0 & $26.8 / 113.4$ \\
\hline $\begin{array}{l}\text { Spinacia-Spinacia } \\
\text { oleracea, } \\
\text { (Amaranthaceae) }\end{array}$ & $\begin{array}{c}90.8 \pm 0.1 \\
\operatorname{RDS}=0.11 \\
n=3\end{array}$ & $\begin{array}{c}3.2 \pm 0.1 \\
\mathrm{RDS}=3.69 \\
n=3\end{array}$ & $\begin{array}{c}2.7 \pm 0.1 \\
\operatorname{RDS}=3.70 \\
n=3\end{array}$ & $\begin{array}{c}0.4 \pm 0.1 \\
\mathrm{RDS}=25 \\
\mathrm{n}=3\end{array}$ & $\begin{array}{c}2.1 \pm 0.1 \\
\operatorname{RDS}=4.76 \\
n=3\end{array}$ & $\begin{array}{c}0.4 \pm 0.1 \\
R D S=25 \\
n=3\end{array}$ & 2.9 & $26.0 / 110.0$ \\
\hline $\begin{array}{l}\text { Rumex-Rumex } \\
\text { patientia, } \\
\text { (Polygonaceae) }\end{array}$ & $\begin{array}{c}91.0 \pm 0.1 \\
R D S=0.11 \\
n=3\end{array}$ & $\begin{array}{c}3.3 \pm 0.1 \\
R D S=3.03 \\
n=3\end{array}$ & $\begin{array}{c}2.2 \pm 0.1 \\
\mathrm{RDS}=4.55 \\
n=3\end{array}$ & $\begin{array}{c}0.6 \pm 0.2 \\
R D S=33.33 \\
n=3\end{array}$ & $\begin{array}{c}2.8 \pm 0.1 \\
R D S=3.57 \\
n=3\end{array}$ & $\begin{array}{c}0.1 \pm 0.08 \\
R D S=65.47 \\
n=3\end{array}$ & 2.9 & $25.8 / 108.9$ \\
\hline $\begin{array}{l}\text { Sorrel-Rumex acetosa, } \\
\text { (Polygonaceae) }\end{array}$ & $\begin{array}{c}90.8 \pm 0.1 \\
\text { RDS }=0.11 \\
n=3\end{array}$ & $\begin{array}{c}3.2 \pm 0.1 \\
\text { RDS }=3.68 \\
n=3\end{array}$ & $\begin{array}{c}2.1 \pm 0.1 \\
R D S=4.76 \\
n=3\end{array}$ & $\begin{array}{c}0.6 \pm 0.2 \\
\text { RDS }=33.33 \\
n=3\end{array}$ & $\begin{array}{c}3.1 \pm 0.1 \\
R D S=3.23 \\
n=3\end{array}$ & $\begin{array}{c}0.1 \pm 0.08 \\
\text { RDS }=65.47 \\
n=3\end{array}$ & 3.3 & $27.0 / 114.0$ \\
\hline $\begin{array}{l}\text { Nettle-Nettle dioica, } \\
\text { (Urticaceae) }\end{array}$ & $\begin{array}{c}86.7 \pm 0.1 \\
R D S=0.12 \\
n=3\end{array}$ & $\begin{array}{c}3.5 \pm 0.1 \\
\text { RDS }=2.86 \\
n=3\end{array}$ & $\begin{array}{c}2.7 \pm 0.1 \\
\mathrm{RDS}=3.70 \\
n=3\end{array}$ & $\begin{array}{c}0.1 \pm 0.08 \\
\mathrm{RDS}=65.47 \\
\mathrm{n}=3\end{array}$ & $\begin{array}{c}6.3 \pm 0.1 \\
\mathrm{RDS}=1.59 \\
\mathrm{n}=3\end{array}$ & $\begin{array}{c}0.3 \pm 0.1 \\
\mathrm{RDS}=33.33 \\
\mathrm{n}=3\end{array}$ & 7.0 & $39.7 / 168.6$ \\
\hline
\end{tabular}

Table 2: Total phenolic and total flavonoid contents and DPPH in different herbs.

\begin{tabular}{|c|c|c|c|}
\hline Herbs & Total phenolics, mgGAE/g & Total flavoniods, $\mathrm{mgCE} / \mathrm{g}$ & DPPH IC $_{50}, \mathrm{mg} / \mathrm{ml}$ \\
\hline Atriplex-Atriplex hortensis, (Amaranthaceae) & 192.15 & 144.74 & 1.90 \\
\hline Spinacia-Spinacia oleracea, (Amaranthaceae) & 182.52 & 113.81 & 2.20 \\
\hline Rumex-Rumex patientia, (Polygonaceae) & 179.50 & 109.62 & 1.26 \\
\hline Sorrel-Rumex acetosa, (Polygonaceae) & 169.20 & 105.43 & 1.67 \\
\hline Nettle-Nettle dioica, (Urticaceae) & 212.80 & 133.92 & 1.20 \\
\hline
\end{tabular}

\section{Total phenolic and total flavonid contents amd DPPH in different herbs.}

- Total phenolics, mgGAE/g - Total flavoniods, mgCE/g $\square$ DPPH IC50, mg/ml

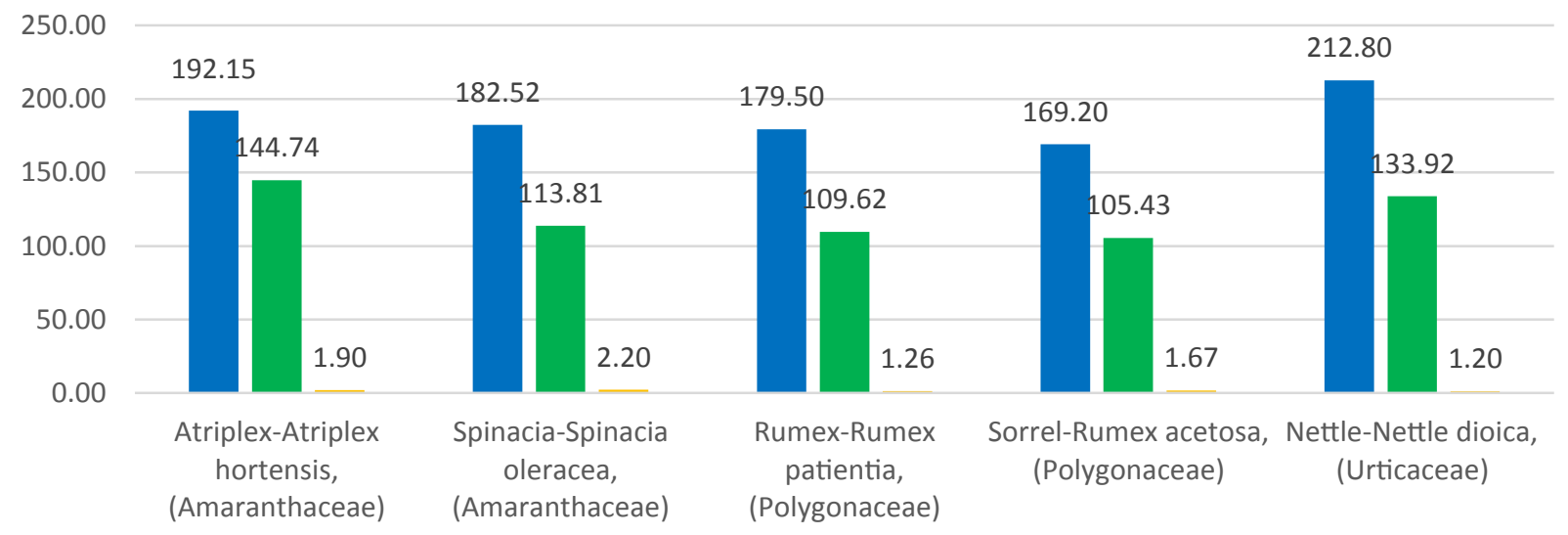

Figure 1: Total phenolic and total flavonoid contents and DPPH in different herbs. 
be fairly significant when compared to the methanol extracts of Atriplex (Atriplex hortensis), Rumex (Rumex acetosa), Rumex (Rumex patientia) and Urtica (Urtica dioica). Further, $\mathrm{IC}_{50} \%=2.20 \mathrm{mg} / \mathrm{ml}$ methanolic extract of Spinacia (Spinacia oleracea) was necessary to obtain $50 \%$ of DPPH degradation.

It is discernible from the data in Table 1 that the insoluble dietary fibre (ISD) in different herbs ranges between $2.1 \%-6.3 \%$. The highest $(6.3 \%)$ amounts of insoluble dietary fibers (IDF) were found in the nettle followed by Rumex acetosa $(3.1 \%)$, Rumex (2.8\%), Atriplex (2.2\%) and lowest in Spinacia.

Concerning nutrition facts in spring herbs the contents of lipids is relatively low. At the same time the contents of proteins in plants is negligible (between $2.1 \%$ and $2.8 \%$ ), with highest value in Atriplex 2.8\%.

Furthermore, the concentration of sugar is also very less and ranges between $0.1 \%-0.5 \%$ with maximum concentration in Atriplex (0.5\%), followed by Spinacia $(0.4 \%)$, and minimum in Rumex and Rumex acetosa. The carbohydrates in different herbs vary from $2.9 \%-7.0 \%$ with highest (7.0\%) in Urtica and lowest in Spinacia and Rumex acetosa. The Nettle also contains high levels of energy value $168.6 \mathrm{~kJ} / 100 \mathrm{~g}$ in comparison to Rumex $108.9 \mathrm{~kJ} / 100 \mathrm{~g}$.

The ash content is also one of the important characteristic that signifies the mineral content to some extent of the food material. It is clearly seen from the data in Table 1 that ash content in different herbs collected from Bulgarian market ranges between $3.1 \%-3.5 \%$ with maximum content in Rumex acetosa and minimum in Spinacia and Rumex.

\section{Conclusion}

The study indicated that spring herbs are a potential source of nutritionally valuable components and its consumption improves antioxidant status. The high level of the total polyphenol content in herbs influences the high antioxidant activity. All dietary fibers are found in spring herbs. As the insoluble dietary fibers (IDF) are those that do not dissolve into the water, the intestinal colon bacteria cannot use them as a food source. Diet rich in dietary fibers and low in fat reduces the risk of overweight and helps to maintain the desirable blood glucose level. The results from the analysis of spring herbs show specific insoluble dietary fibers has been linked to a lower risk of heart disease in a number of large studies that followed people who wanted to regulate their weight control problems in the right direction and nutritionists who prepared a healthy and rich diet. The lipid contents in herbs the contents of lipids are relatively low. The contents of proteins in the plant are negligible. The contents of sugar and carbohydrates are also more important in spring herbs. The results can be used in public health campaigns to stimulate the consumption of natural product as spring herbs able to provide significant health protection in order to prevent chronic diseases.

\section{References}

1. Wegener G. 'Let food be thy medicine, and medicine be thy food': Hippocrates revisited. Acta neuropsychiatr. 2014;26:1-3.
2. Rasouli H, Farzaei MH, Khodarahmi R. Polyphenols and their benefits: A review. Int J Food Prop. 2017;20:1700-41.

3. Hedges LJ, Lister CE. Nutritional attributes of herbs, crop and food. Research Confidential Report, A report presented for Horticulfare New Zealand. 2007;42.

4. Rahul A, Subhash D. Total phenolic, total flavonoid content and antioxidant activity of leaves extracts of Chenopodium album $L$ and Atriplexhortensis L. Int Journal Curr Res. 2017;9:52430-4.

5. Lobo V, Patil A, Phatak A, et al. Free radicals, antioxidants and functional foods: Impact on human health. Pharmacogn rev. $2010 \mathrm{Jul} ; 4: 118$.

6. Atanassova M, Ribarova F. Physicochemical Analyses of Natural Juices, Dry Fruits and Vegetables Collected for Bulgarian Markets, Int J Curr Chem. 2011;2:449-58.

7. Atanassova M, Vatralova K, Kostadinova K. Revue electronique. Int pour la sci et la technol. 2009;1:18-28.

8. Smara O, Dendougui H, Legseir B. The Flavonoids for a plant grows in the arid and semi-arid zone of the northern Sahara ofAlgeria-Atriplex HalimusL. Der Pharma Chemica. 2016; 8:12-6.

9. Bystricka J, Musilova J, Tomas J, et al. Varietal dependence of chemoprotective substances in fresh and frozen spinach (Spinacia oleracea L.). Potravinarstvo Slovak. J Food Sci. 2015;9:468-73.

10. Koh E, Charoenprasert S, Mitchell AE. Effect of organic and conventional cropping systems on ascorbic acid, vitamin $\mathrm{C}$, flavonoids, nitrate, and oxalate in 27 varieties of spinach (Spinacia oleracea L.). J Agricul Food Chem. 2012;60:314450.

11. Bacchetti T, Tullii D, Masciangelo S, et al. Effect of a barleyvegetable soup on plasma carotenoids and biomarkers of cardiovascular disease. J Clin Biochem Nutr. 2015;57:6673.

12. Rao KN, Tabassum B, Babu SR, et al. Preliminary phytochemical screening of Spinacia oleracea L. World J Pharm Pharm Sci. 2015;4:532-1.

13. Pandey KB, Rizvi SI. Plant polyphenols as dietary antioxidants in human health and disease. Oxid Med and Cell Longev. 2009;2:270-8.

14. Ferreres F, Ribeiro V, Izquierdo AG, et al. Rumex induratus leaves: Interesting dietary source of potential bioactive compounds. J Agricul Food Chem. 2006;54:5782-9.

15. Bae JY, Lee YS, Han SY, et al. A comparison between water and ethanol extracts of Rumex acetosa for protective effects on gastric ulcers in mice. Biomole therapeut. 2012;20:425.

16. Isbilir SS, Sagiroglu A. Total phenolic content, antiradical and antioxidant activities of wild and cultivated Rumex acetosella L. extracts. Bio Agri \& Horti. 2013;29:219-26.

17. Bourgeois C, Leclerc EA, Corbin C, et al. Nettle (Urtica 
dioica L.) as a source of antioxidant and anti-aging phytochemicals for cosmetic applications. Comptes Rendus Chimie. 2016;19:1090-100.

18. Singleton VL, Rossi JA. Colorimetry of total phenolics with phosphomolybdic-phosphotungstic acid reagents. Am J Enol Vitic. 1965;16:144-58.

19. Marinova D, Ribarova F, Atanassova M. Total phenolics and total flavonoids in Bulgarian fruits and vegetables. J Uni Chem Technol Metallurgy. 2005;40:255-60.

20. Bondet V, Brand-Williams W, Berset C. Kinetics and mechanisms of antioxidant activity using the DPPH free radical method. LWT-Food Sci Technol. 1997;30:609-15.

21. https://www.iso.org/member/1597.html

22. Manual "Methods harmonized with the EU requirements".1998:1.

23. Gyurova D, Atanassova M, Tzenkova R. Short communication dietary fibers content in thirteen Bulgarian vegetables. J Uni Chem Technol Metallurgy. 2007;42:117-8.
24. AOAC. Official Methods of Analysis of the Association of Official Analytical Chemistry, $16^{\text {th }}$ edition, 1995.

25. Bligh EG, Dyer WJ. A rapid method of total lipid extraction and purification. Can J Biochem Physiol. 1959;37:911-7.

26. Maria A, Fany R. Physicochemical Analyses of Natural Juices, Dry Fruits and Vegetables Collected for Bulgarian Markets.

27. Shirwaikan A, Rajendran K, Kumar CD. In vitro antioxidant studies of Annona squamosa. Indian J Exp Biol. 2004;142:803.

28. Uysal S, Cvetanovic A, Zengin G, et al. Effect of Orange Leaves Extraction Conditions on Antioxidant and Phenolic Content: Optimization Using Response Surface Methodology. Analytical Letters. 2018;51:1505-19.

29. Farasat M, Khavari-Nejad RA, Nabavi SM, et al. Antioxidant activity, total phenolics and flavonoid contents of some edible green seaweed from northern coasts of the Persian Gulf. Iran J Pharm Res: IJPR. 2014;13:163.

\section{*Correspondence to:}

Atanassova $\mathrm{M}$

Department of Chemical Engineering University of Chemical Technology and Metallurgy

Bulgaria

Email: msatanassova@abv.bg 